\title{
Minimizing the Pessimistic Time of Activity in Overhaul Project
}

\author{
Josip JUKIĆ, Roberto LUJIĆ, Dražen BARKOVIĆ
}

\begin{abstract}
The objective of this paper is to analyse some concepts of the project management techniques and the proposed mathematical model for estimating the project completion probability after crashing of PERT/CPM network. The main objective is to minimize the pessimistic time of the activity, which lies on the critical path by investing additional amounts of money to the project. The increment of the investment not only decreases the pessimistic time of the activities along the critical path, but it also decreases the expected time of activities along the critical path of the whole project duration.
\end{abstract}

Keywords: CPM; crashing time; PERT; project management

\section{INTRODUCTION}

Project management as one of the fastest growing fields takes into consideration not only planning and managing of necessary resources (people, equipment, materials, etc.) but technical and time constraints and project cost, as well. Today, the company management has to be able to bring reliable decisions in a limited period. Valid and reliable decisions cannot be made from incomplete and unreliable data and inadequate management models. Practical experience shows frequent delays in the fulfilment of the obligation towards the customer, i.e. the fulfilment of the obligation by the unplanned engagement of additional resources that will result in increased costs. The managing of complex technical systems overhaul and its principles that can be applied in any area will be shown. During the planning and managing of a project, the management is faced with several important issues, and the most important are the length of project and project costs, to which some answers can be given precisely, especially if the project is running for the first time. Such projects that include new activities involve high levels of uncertainty and risk. The problems that can appear during the project life cannot be predicted and neither its impact on the development of the entire business system $[1,2]$.

To provide successful project management, continuous monitoring of the planned resources in the project has to be done. It includes the completion of the project within the planned timeframe and with the anticipated costs [3-5].

Three main project management features are the project schedule, costs that are within the limit of the budget and the quality requirements that are defined by default. Therefore, the duration and costs are the variables that have to be minimized (optimized) [6].

Due to increased industrialization and disposing of a larger amount of electricity, the projects have become more complex than ever. Research in the field of atomic energy, computers, communications, transportation and missile defence systems accelerated the complexity of project activities. Many of the projects are similar to the previous ones, but there are also many projects that are different from the old ones due to advanced technology and increased scope. Once the management realized that the projects are not just for a narrow circle of engineers, project management has become one of the more complex forms that cannot be seen only as a managerial approach but as a science, and in practice it is actually a profession [7].

Project management is a relatively new way of managing activities that are of particular importance in the manufacturing and service industries.

To achieve the goals within a certain time, costs and constraints, the conceptual view of project management is defined through planning, organizing, managing and controlling of processes and resources [8].

The above definition includes a partial description of what the project actually is. The following definition serves as a supplement: the project is each series of activities or affairs with a specific irreversible unique goal that has to end within a certain time, cost, performance constraints, has specific start and end dates, resource usage and is not repeatable.

A large percentage of uncertainty is present in the project. Calculating elements (price of materials, price of parts, service prices, co-operation, and other operating costs) are calculated with certain estimates, and the continuous control and analysis of the calculated and realized costs is required.

It requires from the project management system a great flexibility and quick consideration of the current state of resources and preparedness of the manufacturing process or overhaul, making variants of the plan with the expected costs and quick rebalancing of the plan for the time periods with the retention or shortening of ending dates, of course with quality retention.

The most common problems in the project management are inadequate resources, meeting unrealistic deadlines, ambiguous goals, irresponsibility of individual team members, insufficient and superficial planning, lack of communication, goals and resource changes, conflicts between departments and functions [9].

Between the methods, there are differences in the way of displaying and calculating relevant times. Depending on the type of project for which network planning can be applied, some way of displaying can be simpler and most appropriate. The methods of network programming have primarily put in the first plan the strict time planning and time control. Scheduling time in implementing a project is performed by an analysis that is marked with two steps. The first step concerns the analysis of the project structure, which implies a logical sequence of interdependent 
activities (affairs). The next step is to analyse the time to determine the earliest and the latest occurrence of the event and the critical path in the network.

Additional desires appear comparatively to the practical application of network planning. There is a dependency between the length of activities and costs associated with this activity. If the concept of costs is understood relatively broadly, this fact becomes particularly clear: as soon as a project is completed, the workforce and machines can sooner be included in another project that brings a new gain. This can be expressed differently: the delay in the first project entails the delayed start of the second project and the consequence is the loss of the gain related to the delay time. The gains that have thus elapsed can be understood as costs, so-called "opportunity costs". This, however, can mean: even if the actual costs of a project are increased by cutting some particular activity, the enterprise can take advantage as its productive forces can be engaged in the new tasks that provide some gain.

Reflections in this direction initiate the need to associate the time-based analysis with the network programming with cost-based observation. So far, a number of methods that take into account the costs along with the usual time analysis have been developed. At this point, another extension of time planning related to the processing of the restriction capacity should be mentioned. When implementing certain activities of a project, a limited number of workforce, machinery, and so on is available. That is why only some requirements that are within the limits of the company's available capacity can be met. A particular meaning in the network planning has the processing of capacity restriction where multiple parallel projects occur. Planning of the utilization of workforce and machinery is important here, as well as determining the duration of a particular activity.

For some time, Critical Path Method (CPM) and / or Project Evaluation and Review Technique (PERT) have been used for planning, managing and controlling of projects. These tools allow the project managers to define the earliest beginnings and the latest endings of specific activities (time slack), calculate the duration of activity and the total duration of the project, define the critical activities and evaluate the impact of changes on the duration of certain activities and the ability to link disturbance effects (prolongation / shortening of duration and/or decrease/ increase in costs [10].

CPM establishes the relationships between the project activities. The key person and other resources can be allocated to the activities on the critical path. These activities can be closely monitored to avoid completion delays. CPM identifies the sequence of activities that will have the longest completion time of the entire project.

The procedure known as PERT - Program Evaluation and Review was developed in 1958 and uses the probability calculus and mathematical statistics maximally to determine the duration of certain activities and other network parameters.

PERT expands the scope of CPM especially for solving the uncertainty of any project. The companies that use different decision-making tools give priority to network planning. Even though these techniques are widely used in practice and provide economic benefits to the end users, they have certain problems. The problems are the result of the nature of basic statistical assumptions, the potential for high computer costs and assumption that the factors that determine the duration of the activity are essentially probabilistic rather than determined by the management [1].

With the CPM method, a system for planning of work maintenance and general overhaul in the chemical (process) industry was elaborated for the first time. However, there are numerous projects (scientific research, developmental, etc.) whose nature is not compatible with the assumption of estimated time of activity as a deterministic size. In such cases, the duration of activity is necessary to be seen as random size, which should be adapted to the process of calculating the time parameters.

The theoretical framework of network planning should be a theme of all the relevant literature on our topic.

According to literature, Adlakha and Arsham (1992), based on various methodological analyses of network planning and issues related to it, give an extensive review. Stochastic Activity Network is a very interesting alternative to CPM/PERT. According to Stochastic Activity Network, the same project has to be performed in an equivalent way, with the knowledge of the time distribution function used in Monte Carlo simulation experiments to determine the expected CPM/PERT duration. There are several practical disadvantages especially connected with computer expansion. Kallo, 1996; Kamburowski, 1997; Keefer and Verdini, 1993; Kuklan, 1993 claim that the validity of the abovementioned assumptions is the area raising enduring questions for scholars. According to Nakashima (1999), the incorrect inputs will result in the incorrect CPM / PERT designation, and if the complexity of the project is increased, the accuracy of the results will decrease. Hasan and Gould (2001) support the idea of creating a sensemaking managers activity but they are seeking for more complex user data. Modern decision support systems, in spite of uncertainties, are more eligible for project management than CPM/PERT according to Trietsch and Baker (2012). Czuchra (1999) gives some recommendations for optimizing the budget spending for the software implementation and testing. Many authors are potential changes in the statistical variables when researching network. Mouhoub, Benchocine and Belouadah (2011) suggest that the number of dummy activities has to be reduced as much as possible. Herrerı'as Velasco, Herreri'as-Pleguezuelo and Rene van Dorp (2011) suggest changes in the PERT variance expression, while Martin, Garcia, Perez and Sanchez Granero (2012) propose a two-sided power and the generalized biparabolic distribution instead of the existing PERT methodology.

According to the short project duration, the network crashing has to be done by using the additional resources. Crashing in CPM means selecting the lowest cost activities, which will shorten the critical path. The idea of project crashing is not developed in PERT where stochastic time estimates were [11].

A research shows development and application of a mathematical modelling technique with linearized Taylor's first order expansion and solving by the simplex method. The main objective is minimisation of the pessimistic time of the activity that lies on the critical path by investing the 
additional amounts of money in the project. The increased amount of money invested in the project will stream towards minimisation of the pessimistic time in the manner to decrease the expected time and project duration and simultaneously reduce its variance and standard deviation. Increasing the probability or percentage of completing the project on or before completion time is the research result. The theoretical basis of network planning takes into consideration important points of view: activity duration, approximation of activities through beta distribution, calculation of expected activity value by weighted average of three chosen times $(a+4 m+b) / 6$, calculation of standard deviation and variance for each activity. The critical path using the mean activity completion times determines the distribution of the project completion time. The project completion time distribution is normal [12].

Modern approaches to the organization of overhauling technical systems set the task of rationalizing the organization of the maintenance function to the company in order to shorten the cycle itself, the preparation times, as well as the time and energy consumption per unit of time but also the total cost. Such approaches improve the quality of completed work, increase resource utilization through planning and overhaul planning.

Today, the company's management demands that in the shortest possible time the more reliable decisions are made. The importance of making timely and valid decisions cannot come from unreliable and incomplete data or inadequate management models. Today's decisions and the ability to meet the deadlines are largely done by assessing the duration, customer requirements and competitive bids, not taking into account the actual conditions and capabilities of their own resources and capacities.

There are numerous examples of large investment projects that are questioned due to the overrun of the deadline for construction, and hence the cost of the project and investment has made it irrational even before the start of the realization. Classical planning and management methods have not met such development requirements and Network Planning Technique has become an irreplaceable technique for planning and managing very complex projects.

Network Planning Technique does not break the relationship with the classical planning methods but strives to complete it, make it more elastic and provide a more complex picture of the project and thus enable more efficient process management.

This paper analyses the time and cost duration of the activity as random quantities using the PERT-COST method as an example of overhauling a complex technical system using the POM-QM for Windows information program.

Time and cost analysis is performed in the following steps:

- Collecting basic activity data

- Estimate of the activity duration and calculation of variables of expected time duration

- Time analysis and determination of critical time

- Determining the time reserve and probability of occurrence of events

- Determination of optimal direct costs.

\section{COLLECTION OF BASIC ACTIVITY DATA}

During the organization of the production process of overhaul, special significance is attached to the time factor. Therefore, the basic task of the organization during the overhaul is to choose such a variant of an organization that enables entrepreneurship [13].

For each type of STS the time duration and extent of overhaul, which is usually expressed in hours, are determined.

The technological process of overhaul is also elaborated for each asset. Elaboration of the technological process of overhaul STS is implemented as follows [13]:

- making the general scheme of the technological process by separating it into its constituent elements (phases, operations, procedures),

- determination of necessary tools, equipment and instruments,

- determination of the machining parameters (e.g. for machines, welding, metallization, etc.),

- determining the qualification structure of employees (for each operation),

- determination of normative for each phase, operation and procedure,

- determining the order of quality control of work,

- making the plan variants of overhaul and selecting the most favourable versions of the plan.

\section{ESTIMATE OF THE ACTIVITY DURATION AND CALCULATION OF VARIABLES OF EXPECTED TIME DURATION}

There are many projects whose nature was not consistent with the assumption of the estimated duration time of activities as a deterministic size. The overhaul is such a project especially when it is done for the first time. It can be started from the fact that for each activity and in stochastic terms, the ultimate limits (minimum and maximum duration) and the most probable duration of the activities can be estimated [14].

The estimated duration time of the main activities for the development of time schedule of overhaul of a complex technical system is indicated in Table 1.

There are several possible methods for determining the duration of an activity, which depends primarily on the organizational level of the enterprise. When applying the norms determined by some of the methods of study of work and time, the evaluation of the duration of the activity will be more precise, and thus calculated time parameters from the network diagram more reliable. The duration of the activity cannot be taken directly from the norms, especially if the project is being run for the first time, but must be calculated because the individual activities can cover a larger or smaller volume of work. Naturally, the network diagram must also include activities that are not standardized but must be evaluated (waiting for management decisions, deadline for delivery of parts, materials, tools, etc.). When assessing the duration of such activities, it is advisable to consult with the persons responsible that are involved in the realization of the activity and ultimately increase the responsibility towards the deadlines. 
Based on the above considerations, it can be concluded that for each activity it is necessary to be estimated.

The most widely used CPM/PERT algorithm is based on the following assumptions and procedure [1]:

- $a_{i j}$ - optimistic activity duration represents the time duration of the activities that can only occur under very favourable conditions and very favourable circumstances when performing it. Such a favourable course of activity may happen with the probability of $5 \%$.
- $m_{i j}-$ most probable activity duration is the time duration of an activity that has in practice the highest individual probability of achieving.

- $\quad b_{i j}$ - pessimistic activity duration represents the time duration of activities that can only occur in very unfavourable and unlucky circumstances of carrying out a certain activity. Such a case might happen with the probability of $5 \%$.

Table 1 Activities and estimated duration

\begin{tabular}{|c|c|c|c|c|c|c|c|}
\hline$k$ & $i$ & $j$ & Activity's name & $a_{i j}$ & $m_{i j}$ & $b_{i j}$ & $t_{e}$ \\
\hline 1 & 1 & 2 & STS admission and determining the technical condition & 10 & 12 & 16 & 12,33 \\
\hline 2 & 1 & 3 & Dismantling the engine from the vehicle, detailed engine and auxiliary system overview & 20 & 24 & 30 & 24,33 \\
\hline 3 & 2 & 3 & Fictive activity & 0 & 0 & 0 & 0 \\
\hline 4 & 2 & 5 & Removal of auxiliary systems from the engine (high pressure pump, electro-rotator, ...) & 16 & 16 & 20 & 16,67 \\
\hline 5 & 2 & 7 & Removing the cylinder head together with the assemblies & 14 & 14 & 20 & 15 \\
\hline 6 & 3 & 4 & Piston and coupling clamping force and gauge measurement & 18 & 20 & 22 & 20 \\
\hline 7 & 3 & 6 & Cylinder head disassembling, replacement of valve assemblies and assembly & 25 & 30 & 40 & 30,83 \\
\hline 8 & 4 & 8 & Fictive activity & 0 & 0 & 0 & 0 \\
\hline 9 & 4 & 10 & Replacement of piston rings and cylinder liner installation & 13 & 16 & 22 & 16,5 \\
\hline 10 & 5 & 12 & Piston ring sealing test and piston stroke & 4 & 4 & 6 & 4,33 \\
\hline 11 & 6 & 7 & Fictive activity & 0 & 0 & 0 & 0 \\
\hline 12 & 6 & 8 & Fictive activity & 0 & 0 & 0 & 0 \\
\hline 13 & 6 & 9 & Setting the cylinder head to the engine & 8 & 8 & 12 & 8,67 \\
\hline 14 & 7 & 12 & Testing the engine on the test bench & 8 & 8 & 21 & 10,17 \\
\hline 15 & 8 & 9 & Installing auxiliary systems on the motor & 13 & 16 & 20 & 16,17 \\
\hline 16 & 9 & 10 & Fictive activity & 0 & 0 & 0 & 0 \\
\hline 17 & 9 & 11 & Auxiliary systems testing within the engine & 8 & 10 & 14 & 10,33 \\
\hline 18 & 10 & 11 & Installing the motor on the vehicle & 14 & 18 & 28 & 19 \\
\hline 19 & 11 & 12 & Testing the STS driving characteristics & 20 & 22 & 28 & 22,67 \\
\hline
\end{tabular}

This paper presents an example of a remediation scheme for a freight vehicle using the PERT / COST method. After the expiration of a certain amount of resources (mileage), vehicle repairs, replacement of all defective parts and test performance are required.

Only the major activities are listed in the plan and Estimated Time for the Engine of the Subject Vehicle (STS) where the valve assembly and sealing rings on the engine piston have to be replaced. Although this project is not being run for the first time, it is not possible to define all those parts that need to be replaced extensively (subsequently detected malfunctions and damage). Pessimistic time takes into account the longer duration of repairs and the replacement of those parts, which are not anticipated by the overhaul technology.

By introducing another shift, by increasing the number of employees, and by purchasing more sophisticated tools and equipment, etc., it is also possible to speed up the process of overhauling (shorten the duration of activities). The following assumptions are introduced:

- The required number of employees is constantly available

- All the necessary parts are available or it is possible to obtain them at scheduled time

- It is not possible to shorten some of the activities below the expected time (e.g. the duration of the test prescribed by the technology).

\section{PERT FOR PROJECT COMPLETION PROBABILITY}

PERT is a management technique to estimate the probability that a project will finish on time. According to the traditional PERT technique, the probability of a certain project meeting a specific schedule time $T_{\mathrm{S}}$ for a particular event is equal to $f(U)$, probability can be described as follows [3]

$U=\frac{T_{\mathrm{P}}-T_{\mathrm{E}}}{\sigma_{\mathrm{CP}}}$,

Where $U$ is the number of standard deviation of the due date or target date comes from the mean or expected date.

$T_{\mathrm{E}}$ is the normal expected time, which is equal to the sum of normal, expected times of activities on the critical path:

$T_{\mathrm{E}}=\sum_{i=1}^{k} t_{i}, i=1,2, \ldots, k$,

$T_{\mathrm{P}}$ is the target date of completion and $\sigma_{\mathrm{CP}}$ is the project standard deviation, which is written as

$\sigma_{\mathrm{CP}}=\sqrt{\sigma_{1}^{2}+\sigma_{2}^{2}+\cdots+\sigma_{k}^{2}}$,

The expected time and variance of activity on the critical path is computed by the formulas:

$$
\begin{gathered}
t_{i}=\frac{a_{i}+4 m_{i}+b_{i}}{6}, \\
\sigma_{i}^{2}=\frac{\left(b_{i}-a_{i}\right)^{2}}{36},
\end{gathered}
$$


where $a$ is the optimistic activity time, $m$ is most likely the activity time, $b$ is a pessimistic activity time.

Suppose that the amount of money invested in each critical path activity is $c_{i}$ where $i=1,2, \ldots, k$ and $k$ is the number of activities on the critical path. The total extra invested money is $C$ and it can be written as

$$
C=\sum_{i=1}^{k} c_{i},
$$

To minimize the expected project duration $T_{\mathrm{E}}$ to $T_{\mathrm{E}}^{\&}$ and the project standard deviation $\sigma_{\mathrm{CP}}$ to $\sigma_{\mathrm{CP}}^{\&}$, the pessimistic time of critical activities $b_{i}$ to $b_{i}^{\&}$ was reduced.

Then the mathematical models for new $T_{\mathrm{E}}$ and $\sigma_{\mathrm{CP}}^{\&}$ stand

$T_{\mathrm{E}}^{\&}=\min \cdot T_{\mathrm{E}}$

The new expected time for the critical path activities (8)

$t_{i}^{\&}=\frac{a_{i}+4 m_{i}+b_{i}^{\&}}{6}$,

s/t. $b_{i}^{\&} \leq b_{i}$.

The decreasing of pessimistic time $b_{i}$ of the critical path activities depends on the increasing of cost $c$ for each activity on the critical path. Therefore, it means that the decrease in both expected time and variance of activities will be the function $f$ and $\varphi$ of additional investment. Then the new pessimistic time and variance of the activities for the critical path activities will be

$b_{i}^{\&}=b_{i}-\varphi\left(c_{i}\right)$ and $\sigma_{i}^{\&}=\sigma_{i}-\varphi\left(c_{i}\right)$

$c_{i} \geq 0$

Combining all the constraints from (8) and (9) along with the time function (7), the following mathematical model has been obtained:

\section{Time model}

$T_{\mathrm{E}}^{\&}=\min . T_{\mathrm{E}}$

subject to

$t_{i}^{\&}=\frac{a_{i}+4 m_{i}+b_{i}^{\&}}{6}, b_{i}^{\&}=b_{i}-\varphi\left(c_{i}\right), \sigma_{i}^{\&}=\sigma_{i}-\varphi\left(c_{i}\right)$,

$b_{i}^{\&} \leq b_{i}$ and $c_{i} \geq 0$.

After reducing the expected time, the probability of the project completion on or before the targeted time increased to $U^{\&}$. Then the mathematical form of the objective function can be written as

$U^{\&}=\max \cdot U=\frac{T_{\mathrm{P}}-T_{\mathrm{E}}^{\&}}{\sigma_{\mathrm{r}}^{*}}$
For getting the increased probability, the project duration $T_{\mathrm{E}}$ and the project standard deviation $\sigma_{\mathrm{CP}}$ have to be decreased, and can be written as

$T_{\mathrm{E}}^{\&}<T_{\mathrm{E}}$

and

$\sigma_{\mathrm{CP}}^{\&}<\sigma_{\mathrm{CP}}$

Combining all the constraints (13), (14), (11) and (9) along with the probability function (12), the following mathematical model can be made [15]:

\section{Probability model}

$Z^{\&}=\max \cdot Z=\frac{T_{\mathrm{P}}-T_{\mathrm{E}}^{\&}}{\sigma_{\mathrm{CP}}^{\&}}$,

s/t. $T_{\mathrm{E}}^{\&}<T_{\mathrm{E}}, \sigma_{\mathrm{CP}}^{\&}<\sigma_{\mathrm{CP}}, b_{i}^{\&} \leq b_{i}$ and $c_{i} \geq 0$.

\section{NUMERICAL APPROACH FOR CRASHING PERT/CPM NETWORKS}

The project takes into consideration 19 activities. Optimistic time $(a)$, most likely time $(m)$, pessimistic time (b) and immediate predecessor of each activity, are shown in Tab. 2 [16].

Table 2 Optimistic time $(a)$, most likely time $(m)$, pessimistic time $(b)$ and immediate predecessor of each activity

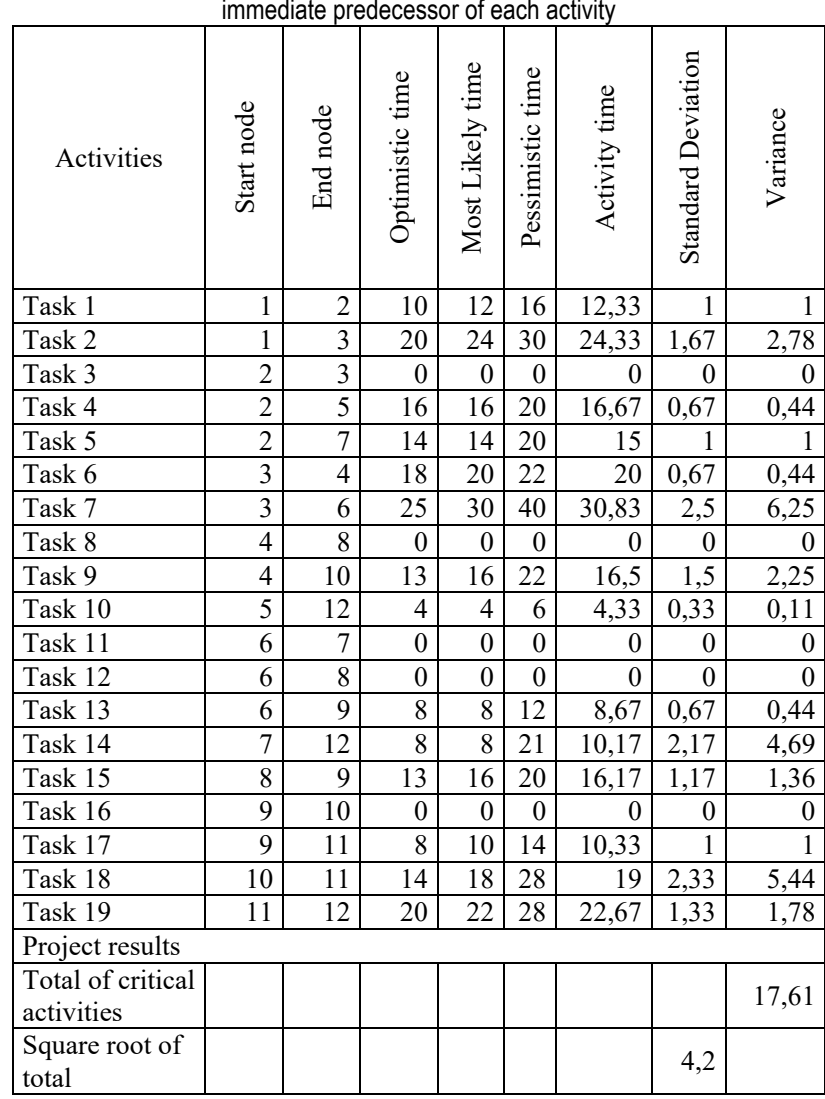

Created by POM-QM for Windows

The activities with slack 0 are on the critical path of the network which is indicated with a red line in Fig. 1. From Tab. 2, the critical path is 1-3, 3-6,6-8, 8-9, 9-10, 1011, 11-12. 


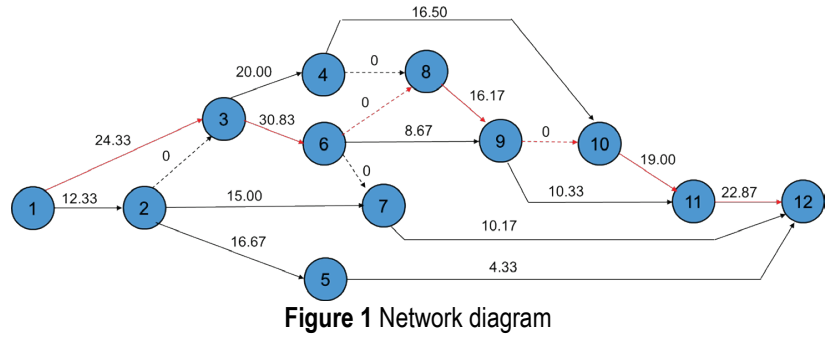

The expected project completion date is

$T_{\mathrm{E}}=24,33+30,83+16,17+19,0+22,67=113$

It means that there is a $50 \%$ chance that the entire project will be completed in less than expected 113 days and $50 \%$ chance that it will exceed 113 days.

The project standard deviation is

$\sigma_{\mathrm{CP}}=\sqrt{2,78+6,25+1,36+5,44+1,78}=\sqrt{17,61}=4,20$

If the scheduled duration of the project is 115 , then the probability of finishing the project within the completion date of 115 days can be computed as

$U=\frac{T_{\mathrm{P}}-T_{\mathrm{E}}}{\sqrt{\sum \sigma_{\mathrm{CP}}^{2}}}=\frac{115-113}{\sqrt{17,61}}=0,48$

From the tables, the areas under the standardized normal curve from $-\infty$ to $-U$ and $U$ value 0,48 gives the probability of 0,6844 which means there is $68,44 \%$ chance of completing the project on or before 115 days.

Hence, in order to increase the probability of completing the project on or before 115 days, the total amount of money, $C$, will be invested for all critical activities in the project, so the increase in the investment of the project will tend to increase the probability of completing the project within 115 days.

Table 3 Estimation of $b, t$ and $\sigma$ after the increased budget amount $C_{1}=24550$

\begin{tabular}{|c|c|c|c|c|c|c|c|c|}
\hline Critical activities & 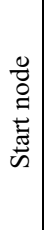 & $\begin{array}{l}\stackrel{0}{0} \\
\stackrel{\Xi}{\Xi} \\
\text { 포 }\end{array}$ & 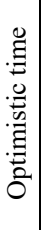 & 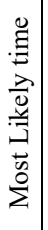 & 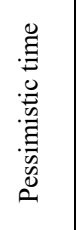 & 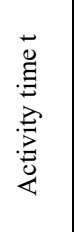 & 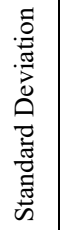 & 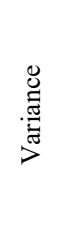 \\
\hline Task 2 & 1 & 3 & 20 & 24 & 28,5 & 24,08 & \begin{tabular}{l|l|}
1,42 \\
\end{tabular} & 2 \\
\hline Task 7 & 3 & 6 & 25 & 30 & 38 & 30,5 & 2,17 & 4,69 \\
\hline Task 12 & 6 & 8 & 0 & 0 & 0 & 0 & 0 & 0 \\
\hline Task 15 & 8 & 9 & 13 & 16 & 19 & 16 & 1 & 1 \\
\hline Task 16 & 9 & 10 & 0 & 0 & 0 & 0 & 0 & 0 \\
\hline Task 18 & 10 & 11 & 14 & 18 & 23,75 & 18,29 & 1,63 & 2,64 \\
\hline Task 19 & 11 & 12 & 20 & 22 & 26,6 & 22,43 & 1,1 & 1,21 \\
\hline \multicolumn{9}{|l|}{ Project results } \\
\hline $\begin{array}{l}\text { Total of critical } \\
\text { activities }\end{array}$ & & & & & & & & 11,55 \\
\hline Square root of total & & & & & & & \begin{tabular}{l|l|}
3,4 & \\
\end{tabular} & \\
\hline
\end{tabular}

According to the new approach presented in this paper, the investment of approximately $C_{1}=24550, C_{2}=49100$, $C_{3}=73650$ extra budgets for the critical path activities was done. All the budgets were specified by the experts having high knowledge in the nature of project activities.
Furthermore, the total amounts of money to be invested in each activity that lies on the critical path, and reduction of $b$ to $b^{\&}$ for each critical activity, are shown in Tabs. 3, 4, 5 [15].

Table 4 Estimation of $b, t$ and $\sigma$ after the increased budget amount $C_{2}=49100$

\begin{tabular}{|c|c|c|c|c|c|c|c|c|}
\hline 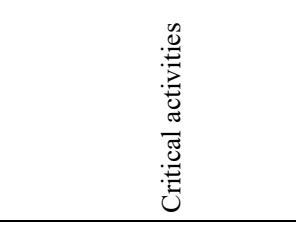 & 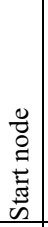 & 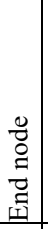 & 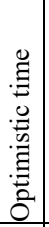 & 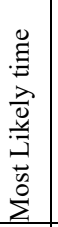 & 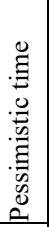 & 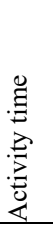 & 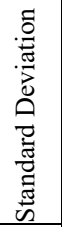 & 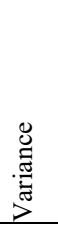 \\
\hline Task 2 & 1 & 3 & 20 & 24 & 27 & 24 & 1,17 & 1,36 \\
\hline Task 7 & 3 & 6 & 25 & 30 & 36 & 30 & 1,83 & 3,36 \\
\hline Task 12 & 6 & 8 & 0 & 0 & 0 & 0 & 0 & 0 \\
\hline Task 15 & 8 & 9 & 13 & 16 & 17 & 16 & 0,83 & 0,69 \\
\hline Task 16 & 9 & 10 & 0 & 0 & 0 & 0 & 0 & 0 \\
\hline Task 18 & 10 & 11 & 14 & 18 & 22 & 18 & 1,33 & 1,78 \\
\hline Task 19 & 11 & 12 & 20 & 22 & 25 & 22 & 0,83 & 0,69 \\
\hline \multicolumn{9}{|l|}{ Project results } \\
\hline Total of critical activities & & & & & & & & 7,88 \\
\hline Square root of total & & & & & & & 2,81 & \\
\hline
\end{tabular}

From Tab. 3:

$T_{\mathrm{E}}^{\&}=\min . T_{\mathrm{E}}=111,3, \sigma_{\mathrm{CP}}^{\&}=3,4$

$U^{\&}=\max \cdot U=\frac{T_{\mathrm{P}}-T_{\mathrm{E}}^{\&}}{\sigma_{\mathrm{CP}}^{\&}}=\frac{115-111,3}{3,4}=1,088$

From the tables, the areas under the standardized normal curve from $-\infty$ to $-U$ and $U$ value 1,088 gives the probability of 0,8621 , which means there is $86,21 \%$ chance of completing the project on or before 115 days.

From Tab. 4:

$T_{\mathrm{E}}^{\&}=\min . T_{\mathrm{E}}=110, \sigma_{\mathrm{CP}}^{\&}=2,81$

$U^{\&}=\max \cdot U=\frac{T_{\mathrm{P}}-T_{\mathrm{E}}^{\&}}{\sigma_{\mathrm{CP}}^{\&}}=\frac{115-110}{2,81}=1,78$

From the tables of areas under the standardized normal curve from $-\infty$ to $-U$ and $U$ value 1,78 gives the probability of 0,9625 which means there is $96,25 \%$ chance of completing the project on or before 115 days.

Table 5 Estimation of $b, t$ and $\sigma$ after the increased budget amount $C_{3}=73650$

\begin{tabular}{|c|c|c|c|c|c|c|c|c|}
\hline \multicolumn{9}{|l|}{ (2) } \\
\hline Critical activities & 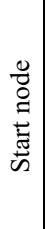 & 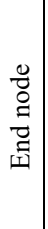 & 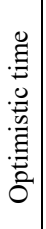 & 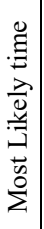 & 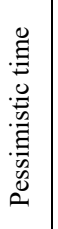 & 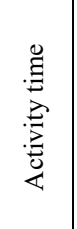 & 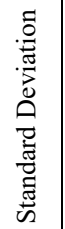 & 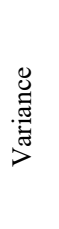 \\
\hline Task 2 & 1 & 3 & 20 & 24 & 25 & 23,50 & 0,83 & 0,69 \\
\hline Task 7 & 3 & 6 & 25 & 30 & 34 & 29,83 & 2,25 & 5,06 \\
\hline Task 12 & 6 & 8 & 0 & 0 & 0 & 0 & 0 & 0 \\
\hline Task 15 & 8 & 9 & 13 & 16 & 16 & 15,50 & 0,25 & 0,06 \\
\hline Task 16 & 9 & 10 & 0 & 0 & 0 & 0 & 0 & 0 \\
\hline Task 18 & 10 & 11 & 14 & 18 & 20 & 17,67 & 1 & 1 \\
\hline Task 19 & 11 & 12 & 20 & 22 & 22 & 21,67 & 0,11 & 0,01 \\
\hline \multicolumn{9}{|l|}{ Project results } \\
\hline Total of critical activities & & & & & & & & 6,82 \\
\hline Square root of total & & & & & & & 2,61 & \\
\hline
\end{tabular}


From Tab. 5:

$$
\begin{aligned}
& T_{\mathrm{E}}^{\&}=\min \cdot T_{\mathrm{E}}=108,17, \sigma_{\mathrm{CP}}^{\&}=2,61 \\
& U^{\&}=\max \cdot U=\frac{T_{\mathrm{P}}-T_{\mathrm{E}}^{\&}}{\sigma_{\mathrm{CP}}^{\&}}=\frac{115-108,17}{2,61}=2,62
\end{aligned}
$$

From the tables, the areas under the standardized normal curve from $-\infty$ to $-U$ and $U$ value 2,62 gives the probability of 0,9956 , which means there is $99,56 \%$ chance of completing the project on or before 115 days.

Tab. 6 gives the overall results.

Table 6 The probability of completing the project
\begin{tabular}{|c|c|c|c|c|c|c|c|}
\hline No & $C$ & $\sum_{i=1}^{k} \sigma_{i}^{2}$ & $T_{\mathrm{P}}$ & $T_{\mathrm{E}}$ & $\sigma_{\mathrm{CP}}^{\&}$ & $U$ & $\%$ \\
\hline 1 & 0 & 17,61 & 115 & 113 & 4,2 & 0,48 & 68,44 \\
\hline 2 & 24550 & 11,55 & 115 & 111,13 & 3,4 & 1,088 & 86,21 \\
\hline 3 & 49100 & 7,88 & 115 & 110 & 2,81 & 1,78 & 96,25 \\
\hline 4 & 73650 & 6,82 & 115 & 108,17 & 2,61 & 2,62 & 99,56 \\
\hline
\end{tabular}

\section{CONCLUSION}

Three different amounts of money $C_{1}=24550, C_{2}=$ 49100 , and $C_{3}=73650$ will be invested in the project to show that the increase of the amount of money invested in the project will tend to minimize the pessimistic time, to decrease the expected time and project duration. At the same time, it also reduces its variance and standard deviation.

As the result of the research, it will bring to the increase of the probability or percentage of completing the project on or before the completion time. The PERT and normal distribution will display the differences between the amounts of money that will be invested in the project.

As Table 6 indicates, the probability of completing the project within 115 days was increased from $68,44 \%$ to $86,21 \%, 96,25 \%, 99,56 \%$, upon the increment of invested amount of money. The expected duration of the project was successfully reduced from 113 days to 108,17 days upon the increase in the amounts of money $24550 \leq C \leq 73650$ to the project.

\section{REFERENCES}

[1] Arsham, H. \& Adlakha, V. (2014). Critical Path Stability Region: A Single-Time Estimate Approach in book: Analyzing Security, Trust, and Crime in Digital World, chapter 3, Publisher IGI Global, Editor Hamid R. Nemati, 35-60.

[2] Ristevski, M., Karakasic, M., Grgic, I., \& Sotola, D. (2018). Technical aspect of CAD and BIM technology in the engineering environment. Tehnicki glasnik-Technical journal, 12(4), 271-274. https://doi.org/10.31803/tg-20180917211402

[3] Nazrul Islam, M., Draghici, E., \& Sharif Uddin, M. (2012). Project Completion Probability after Crashing PERT/CPM Network. Management Sustainable Development, 4, 59-63.

[4] Martinec, T., Skec, S., Savsek, T., \& Perisic, M.M. (2017). Work sampling for the production development: A case study of a supplier in European automotive industry, Advances in Production Engineering \& Management, 12(4), 375-387. https://doi.org/10.14743/apem2017.4.265

[5] Kremljak, Z., Palcic, I., \& Kafol C. (2014). Project Evaluation Using Cost-Time Investment Simulation.
International Journal of Simulation Modelling, 13(4), 447457. https://doi.org/10.2507//JSIMM13(4)5.279

[6] Meredith, J. R. \& Mantel, S. J. (1995). Project Management: A Managerial Approach, New York, John Wiley \& Sons, p. 72.

[7] Barković, D. (2011). Uvod u Operacijski management, Sveučilište Josipa Jurja Strossmayera u Osijeku, Ekonomski fakultet u Osijeku, p. 151. (in Croatian)

[8] Adedorff, S. A. \& de Wit, P. W. C. (1997). Production and Operations Management, International Thompson, Publishing, Johannesburg, p. 149.

[9] Majdandžić, N., Lujić, R., Matičević, G., Šimunović, G., \& Majdandžić, I. (2001). Upravljanje proizvodnjom, Strojarski fakultet u Slavonskom Brodu, Slavonski Brod, p. 170. (in Croatian)

[10] Agyei, W. (2015). Project Planning and Scheduling Using PERT and CPM Techniques with Linear Programming: Case Study. International Journal of Scientific \& Technology Research, 4(8), p. 222.

[11] Abbasi, G. Y. \& Mukattash, A. M. (2001). Crashing PERT networks using mathematical programming. International Journal of Project Management, 19, 181-188. https://doi.org/10.1016/S0263-7863(99)00061-7

[12] Peng, T. W., Bin Mamat, M., \& Bin Dasril, Y. (2010). An Improvement of Numerical Result of Crashing CPM/PERT Network. Journal of Science and Technology, 2(1), 17-32.

[13] Jukić, J. (2000). Prilog razvoju modela upravljanja remontom složenih tehničkih sustava, magistarski rad, Strojarski fakultet, Slavonski Brod.

[14] Stojiljković, M. \& Vukadinović, S. (1984). Operaciona istraživanja, VIZ, Beograd. (in Serbian)

[15] Islam, M. N., Uddin, M. S., \& Khan, A. R. (2014). Crashing PERT/CPM network: Mathematical and numerical approach, Buletinul Institutului Politehnic Din Iasi, Universitatea Tehnica "Gheorghe Asachi" din Iasi, Tomul, p. 72.

[16] Barković, D., Jukić, J., \& Blažević, I. (2017). Cost analysis and project duration shortening in network planning technique with Pert / cost method. Interdisciplinary management research XIII, Opatija, 36-50.

\section{Contact information:}

dr. sc. Josip JUKIC

College of Slavonski Brod

Dr. Mile Budaka 1, 35000 Slavonski Brod, Croatia

E-mail: josip.jukic@vusb.hr

prof. dr. sc. Roberto LUJIĆ

Josip Juraj Strossmayer University of Osijek,

Mechanical Engineering Faculty in Slavonski Brod,

Trg Ivane Brlić Mažuranić 2, 35000 Slavonski Brod, Croatia

E-mail: rlujic@sfsb.hr

dr. sc. Dražen BARKOVIĆ, professor emeritus

Josip Juraj Strossmayer University of Osijek,

Faculty of Economics in Osijek,

Trg Ljudevita Gaja 7, 31000 Osijek, Croatia

E-mail: barkovic@efos.hr 